\title{
Scalp Reconstruction among Neurotrauma Patients: Presentation, Management and Outcome- Single Center Study
}

\author{
Dinesh Kumar Thapa ${ }^{1}$ \\ ${ }^{1}$ Department of Neurosurgery, B\&C medical College Teaching Hospital, Birtamode, Jhapa, Nepal \\ Correspondence: \\ Dinesh Kumar Thapa \\ Department of Neurosurgery \\ B\&C medical College Teaching Hospital, Birtamode, Jhapa, Nepal \\ Email: dineshkthapa@gmail.com \\ Phone no: +9779843123518
}

\begin{abstract}
Background: Scalp laceration is common findings among patients with head injury. It may present with simple laceration, laceration with loss of tissue or degloving type of injury. This study was conducted to observe the different techniques or wound management and fate of thus reconstructed scalp lacerations. Methods and materials: This is a cross-sectional analytical study which was conducted in B\&C Medical College Teaching Hospital, Jhapa, Nepal. Patients presented with major scalp lacerations needing repair in Operation Theatre between June 2017 to May 2019 were included. Age, gender, mode of injuries, severity of the injury, various types of management and complicationswere studied and thus collected data were analyzedin IBM SPSS version 23. Results: There were 53 cases of scalp injuries with male $(75 \%)$ predominance and mean age of 31.51 (SD 15.218) yearsin this study. Road traffic accident was the major cause of injury 28(53\%), followed by physical assault 16(30\%), fall injury $7(13.2 \%)$ and burn injury 2(3.7\%).Primary closure was possible in 29(54.7\%), advancement flap in15(28.3\%), flap rotation in $7(13.2 \%)$ and split thickness skin graft was in $2(3.8 \%)$ patients. Wound infection was seen among $6(11.3 \%)$ patients, wound break down in $2(3.7 \%)$ and flap failure with dehiscence was observed in $1(1.9 \%)$ patient needing secondary healing and closure. Conclusion: Scalp laceration is commonly seen in neurotrauma patients with or with-out intracranial injury. Road traffic accidents top the chart in our part of world.All kinds of scalp laceration can be managed well with different types of surgical techniques.
\end{abstract}

Keyword: Flaps, Head injury, Neuro trauma, Reconstruction, Scalp injury, Scalp laceration.

$\mathrm{S}$ calp laceration is most common among neuro trauma patients. Road traffic accident is the most common mode of injury among neuro trauma patients in Eastern Nepal. ${ }^{1,2}$ Scalp defects may results from different etiologies like trauma, burn, radiation, infection, surgical excision of tumor or other congenital lesions. ${ }^{3}$ Due to lack of elasticity of surrounding tissue, larger defects may need advanced flap, while smaller scalp defects may be closed primarily with simple undermining subgaleal space. ${ }^{4}$ Every scalp defects should be handled well in order to maintain the integrity of skin as well for cosmetic purpose.The reconstruction of large scalp defects could be challenging. The skin of the scalp is thickest in body and divided into the hair-bearing and nonhair-bearing or forehead segment. ${ }^{5}$ There are 52

Date submitted: 5/ 02/2020

Date accepted: 15/04/2020 multiple ways of reconstruction of scalp defects exist, which included primary closure, local flaps, skin grafts, regional or distal free flaps. The methods of reconstruction mainly depend upon etiology, defect size, location and thickness of the defect. $^{3}$

\section{Methods}

This was a cross-sectional analytical study, which was carried out in the Department of Neurosurgery of B and C Medical College Teaching Hospital in between June, 2017 to May, 2019.The patients presented with major scalp lacerations needing reconstruction in Operation Theatre (OT) were include, whereas those who missed follow up, deceased or sutured in Emergency Department were excluded from the study.All flaps reconstructed were caused by different mode of egneuro, Volume 02, Issue 02, 2020 
trauma to scalp.Patients, who had major tissue loss with exposure of scalp bone, were treated with local reconstruction as well as Split Thickness Skin Grafts (STSG), (Figure 1A, 1B).Scalp lacerations lacking approximation or tissue loss were repaired with flap rotation with different methods like Z-plasty, Pinwheel flap technique etc. (Figure 2A, 2B). Primary Closure(PC) was done with proper debridement and approximation of both scalp margins (Figure 3A, 3B). Advancement of Flap (AF) and Flap Rotation(FR) were done in the cases, lacking approximation and significant tissue loss. In the advancement of flaps, the margins of the wounds were advanced either one or both sides, and undermining with galea scoring was done where needed (Figure 4A, 4B).

While doing reconstruction, the major arterial supply of the scalp was preserved to maintain vascular supply to the reconstructed site in order to have good wound healing. Thus, operated cases were collected and non-probability purposive sampling technique was used. The cases were stratified with mode of injury, type of reconstruction done and complications, then processed in IBM SPSS version 23.

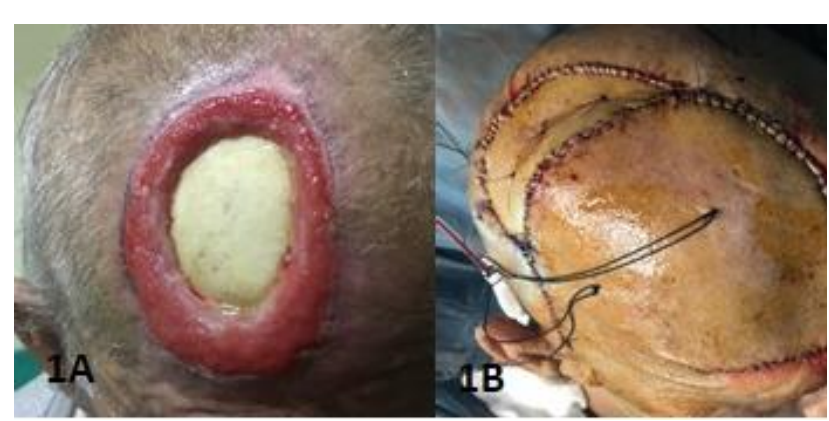

Figure 1A, 1B: A large frontal scalp defect with exposed bone treated with flap rotation and split thickness skin graft (STSG).

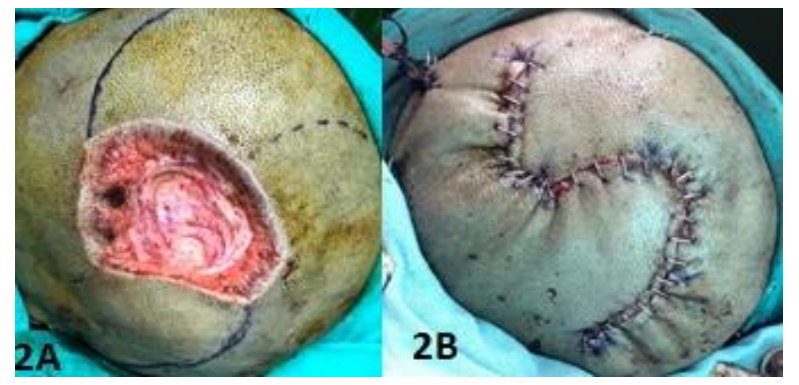

Figure 2A,2B: Rotation flap (FR) with O-Z Plasty was done to reconstruct the parietal scalp defect

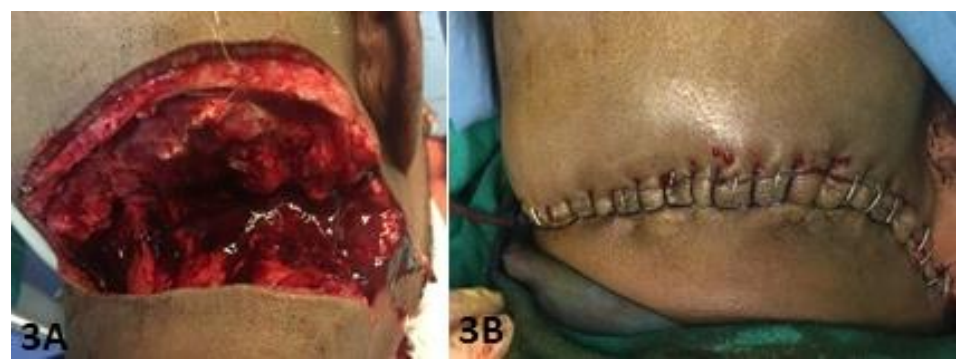

Figure 3A, 3B: Primary Closure (PC) was done for large occipital cut injury

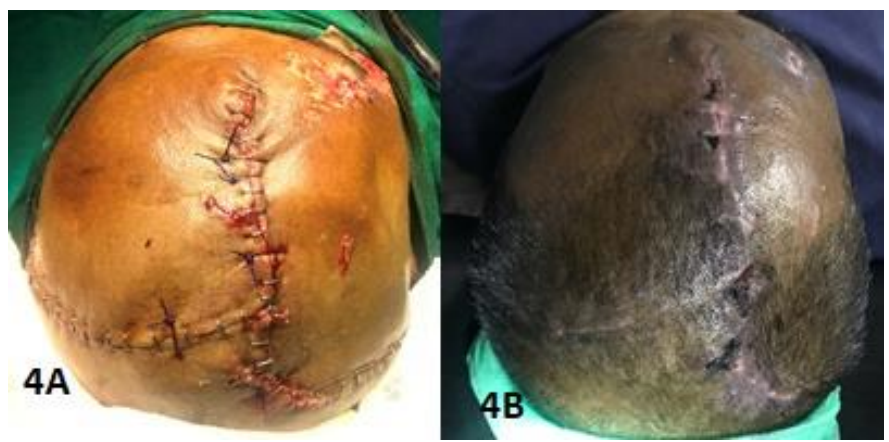

Figure 4A, 4B: After surgery and removal of suture, of a large frontoparietal scalp defect treated with local advancement flap (AF) with galae scoring

\section{Results}

There were total 53 patients enrolled in the study with mean age of 31.51 (SD 15.218) years. There was male $(75 \%)$ predominance in the study sample (Figure5) and majority of the cases were road traffic accidents (53\%) followed by physical assault (30\%)(Figure 6).

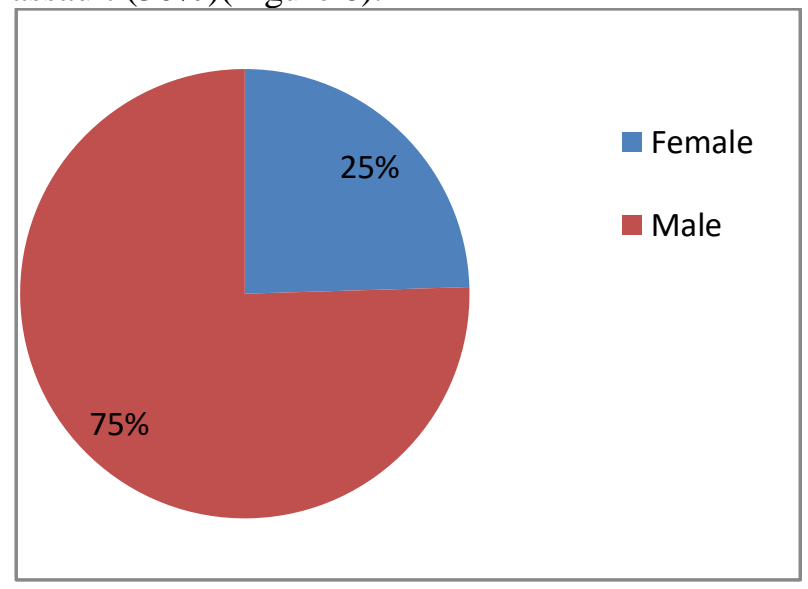

Figure 5: Gender distribution in the study 


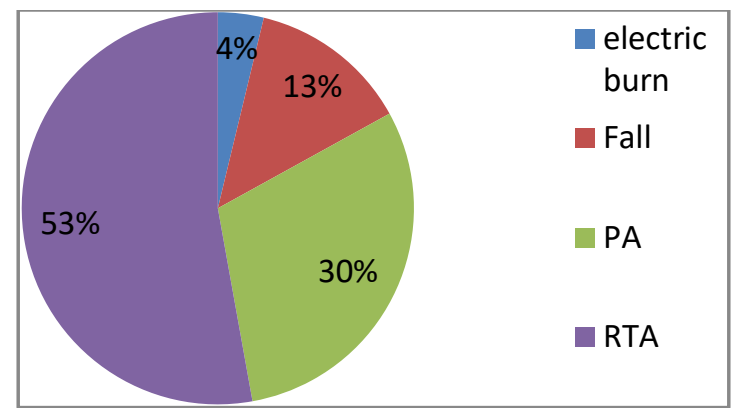

Figure 6: Mode of injury demography.
In majority of the injuries primary closure was possible (54.7\%); however, a significant number still needed advancement flap (28.3\%), and flap rotation (13.2\%) (Table1). There was no complication in $83 \%$ of cases, however $11.3 \%$ had infection and few had wound breakdown and flap failure (Table 1).

Table 1: Frequencies and percentages of various categories

\begin{tabular}{|c|c|c|c|}
\hline & & Frequency & Percent \\
\hline \multirow{4}{*}{$\begin{array}{l}\text { Types of } \\
\text { wound } \\
\text { closure }\end{array}$} & Advancement Flap & 15 & 28.3 \\
\hline & Flap Rotation & 7 & 13.2 \\
\hline & Flap Rotation with STSG & 2 & 3.8 \\
\hline & Primary Closure & 29 & 54.7 \\
\hline \multirow{4}{*}{$\begin{array}{l}\text { Complica } \\
\text { tions }\end{array}$} & No complications & 44 & 83.0 \\
\hline & Flap Failure & 1 & 1.9 \\
\hline & Wound Breakdown & 2 & 3.8 \\
\hline & Wound Infection & 6 & 11.3 \\
\hline
\end{tabular}

Although, there was no significant association between gender and the type of treatment needed. There was significant association of mode of injury and type of treatment needed (Table 2). Gender, Mode of injury and the type of treatment provided were also not associated with the presence or absence of complications following the wound management (Table 3). Similarly there was neither significant association of means of age neither with types of wound closure nor with the complications with $\mathrm{p}$ value 0.269 and 0.638 respectively.

\section{Discussion}

The human scalp is composed of multiple blood supply and its knowledge is essential for selecting the ideal flap type and thus minimizing the complications like flap necrosis. The decisionmaking depends on the size of a defect, anatomic involvement, and overall health of the patient. ${ }^{3,6}$ For aesthetic aspects of reconstruction, most cases of small defects are reconstructed with local flaps. ${ }^{7}$ Also, the primary closure with adjacent tissues should bethe first choice for the closure of small scalp defects. As the scalp tissue has limited elasticity, usually defects less than $5 \mathrm{~cm}^{2}$ (equivalent at less $2,5 \mathrm{~cm}$ of diameter) are supposed for direct primary closure. ${ }^{8}$ Local flaps are the first choice for the repair of defects involving skin, galea, and pericranium. With consideration of the aesthetic aspects of reconstruction, the local flaps might be preferable in most cases of small defects. ${ }^{7}$ The ideal wound to do primary closure is any full-thickness wound where the edges can be opposed with minimal tension which can be used in any part of the scalp.Similarly, in our study, we also have reconstructed most of the cases with primary closure and local advancement flaps. 
Table 2: Association of gender and mode of injury with the type of wound closure

\begin{tabular}{|c|c|c|c|c|c|c|c|}
\hline & & \multicolumn{4}{|c|}{ treatment } & \multirow[b]{2}{*}{ Total } & \multirow[b]{2}{*}{ P Value } \\
\hline & & $\mathbf{A F}$ & FR & $\begin{array}{l}\text { FR with } \\
\text { STSG }\end{array}$ & PC & & \\
\hline \multirow[t]{2}{*}{ Gender } & Female & 5 & 2 & 0 & 6 & 13 & .772 \\
\hline & Male & 10 & 5 & 2 & 23 & 40 & \\
\hline \multirow{4}{*}{$\begin{array}{l}\text { mode } \\
\text { injury }\end{array}$} & electric burn & 0 & 0 & 2 & 0 & 2 & .000 \\
\hline & Fall & 2 & 0 & 0 & 5 & 7 & \\
\hline & $\begin{array}{l}\text { Physical } \\
\text { Assault }\end{array}$ & 9 & 4 & 0 & 3 & 16 & \\
\hline & RTA & 4 & 3 & 0 & 21 & 28 & \\
\hline
\end{tabular}

Table 3: Association of different categories with wound infection

\begin{tabular}{|c|c|c|c|c|c|}
\hline & & \multicolumn{2}{|c|}{ complications } & \multirow[b]{2}{*}{ Total } & \multirow[b]{2}{*}{ P Value } \\
\hline & & no & yes & & \\
\hline \multirow[t]{2}{*}{ sex } & female & 13 & 0 & 13 & .062 \\
\hline & male & 31 & 9 & 40 & \\
\hline \multirow[t]{4}{*}{ Mode of injury } & electric burn & 2 & 0 & 2 & 1.000 \\
\hline & Fall & 6 & 1 & 7 & \\
\hline & PA & 13 & 3 & 16 & \\
\hline & RTA & 23 & 5 & 28 & \\
\hline \multirow[t]{4}{*}{ Treatment } & $\mathrm{AF}$ & 12 & 3 & 15 & 1.000 \\
\hline & FR & 6 & 1 & 7 & \\
\hline & FR with STSG & 2 & 0 & 2 & \\
\hline & $\mathrm{PC}$ & 24 & 5 & 29 & \\
\hline
\end{tabular}

Any full-thickness wound which edges are not approximate with primary closure can be opted for advancement flap(AF), flap rotational (FR) can be considered in full-thickness wounds which can't be closed by most of the advancement flaps.The wound which neither will close with primary closure nor with a flap can go for an STSG. Large scalp defects with devoid of a vascular bed are the good candidates for STSG. ${ }^{6,9}$ Rotation flaps should cover the scalp defect and also should leave minimal donor site morbidity. ${ }^{10}$ Bleeding, secondary infection, failure of the flap, flap necrosis, and pin-cushioning are the common side effects mentioned. ${ }^{11}$ Tissue dehiscence can be resulted by excessive tension or from an infection. Generally, wounds which were dehisced are allowed to heal by secondary intent with revision considered after the wound has healed. If a wound dehisces within 24 hours after surgery another closure can be attempted, however closures after 
this time may increase the risk of infection. ${ }^{6,12} \mathrm{We}$, also observed wound infection is high among road traffic accident patients.

\section{Conclusion}

Scalp reconstructions can be done well in a peripheral setup with competitive results. The highest scalp injuries were caused by road traffic accidents, so as the wound infection seen high in this category of patients. Most of the lacerations caused by trauma can be reconstructed with primary closure and flap advancement, only a few may need advance flaps or skin grafts like STSG or else. Patients with scalp laceration secondary to road traffic accidents have higher chances of wound infection.

\section{Consent}

A written, as well as verbal consent was taken for patients exposed in this study.

\section{Conflict of Interest}

None

\section{References}

1.Yadav AK, Rajbanshi JN, Kushwaha SK, Nepal PR. Prevalence of Head Injury of Patients Arriving in a Tertiary Care Center. Eastern Green Neurosurgery. 2020 Jan 29;2(1):38-41

2. Thapa DK. Review of Neurosurgical services at B\&C Hospital in last 3 years. Eastern Green Neurosurgery. 2019 Apr 30;1(1):2-6.

3.Ebrahimi A, Nejadsarvari N, Ebrahimi A. Reconstructions of small scalp defects with step flap. Journal of cutaneous and aesthetic surgery. 2017 Apr;10(2):106.

4. Beasley NJ, Gilbert RW, Gullane PJ, Brown DH, Irish JC, Neligan PC. Scalp and forehead reconstruction using free revascularized tissue transfer. Archives of facial plastic surgery. 2004 Jan 1;6(1):16-20.

5. Garcíadel Campo JA, García de Marcos JA, del Castillo Pardo de Vera JL, García de Marcos MJ. Local flap reconstruction of large scalp defects.Med Oral Patol Oral Cir Bucal. 2008 Oct 1;13(10):E666-70.

6. Rahmati J, Boroumand S, Ghanbarzadeh K, HaddadyAbianeh S, Molaei H, Fathi A, et al. Reconstruction following Excision of Malignant Scalp Tumors with Split Thickness Skin Graft with and without Acellular Dermal Matrix: A Comparative Study. J CutanAesthet Surg. 2019;12(4):203-11.

7. Mueller CK, Bader RD, Ewald C, Kalff R, SchultzeMosgau S. Scalp defect repair: a comparative analysis of different surgical techniques. Annals of plastic surgery. 2012 Jun 1;68(6):594-8.

8. Cherubino M, Taibi D, Scamoni S, Maggiulli F, Di Giovanna D, DibartoloR, Izzo M, Pellegatta I, Valdatta L. A 56 new algorithm for the surgical management of defects of the scalp.ISRN Plastic Surgery. 2013 Jan 21;2013.

9. Manjunath KN, Venkatesh MS, Vishwanath K. Scalp rotation flap-minor changes major gains. World J Plast Surg. 2016;5:2-6.

10. Leedy JE, Janis JE, Rohrich RJ. Reconstruction of acquired scalp defects: an algorithmic approach. Plastic and reconstructive surgery. 2005 Sep 15;116(4):54e-72e.

11. Divya GK, Shilpa K, Sarvajnamurthy S, Loganathan E, Vasudevan B, Chitrika GB, Madhura C, Lakshmi DV. Outcome of flap surgeries in dermatosurgical unit at a tertiary care centre in India with a review of literature.Journal of cutaneous and aesthetic surgery. 2016 Oct;9(4):226.

12. Prohaska J, Cook C. Rotation Flaps. InStatPearls [Internet] 2020 Feb 13. StatPearls Publishing

13. Mühlstädt M, Thomé C, Kunte C. Rapid wound healing of scalp wounds devoid of periosteum with milling of the outer table and split- thickness skin grafting. British Journal of Dermatology. 2012 Aug;167(2):343-7. 